\title{
AVALIAÇÃO DA ATIVIDADE ENZIMÁTICA DA CREATINO-FOSFO- QUINASE NO SORO DE PACIENTES COM LEPTOSPIROSE *
}

\author{
J. C. Saddy, ${ }^{* *}$ J. J. Pereira da Silva, ${ }^{* * *}$ W. A. Vieira**** e J. R. Coura*****
}

\begin{abstract}
Os autores estudam o comportamento da atividade sérica da CPK em 22 pacientes com leptospirase. Observam sua elevação na fase aguda da doença, em correspondência com as lesões da musculatura estriada evidenciadas ao estudo histológico realizado em 13 casos. Consideram de valor a normalidade dos niveis séricos em pacientes estudados na fase de convalescença, pela sua correlação com os quadrcs clínico e histopatológico. Concluem pela validade da determinação da atividade sérica da CPK como exame complementar ao diagnóstico da leptospirose, bem como à sua distinçấo etiopatogênica dentre as icterícias.
\end{abstract}

\section{INTRODUÇÃO}

Descoberta em 1934 por K. Lohmann, foi a creatino-fosfoquinase (CPK), pela primeira vez, enunciada como de valor diagnóstico, em patologia clínica, por Ebashi e col., em 1959, numa publicação sôbre o seu comportamento, em casos de distrofia muscular progressiva (8). Em 1960, Dreyfus e col. publicam um artigo, "La Creatine-Kinase Serique Dans le Diagnostique de l'Infarctus Myocardique", no qual mostram, não só as elevações da atividade enzimática da CPK nos soros dos pacientes infartados, como, também, fazem referência à sua inalterabilidade, frente a doenças pulmonares e hepáticas, conferindo à enzima em questão valor diagnóstico diferencial importante com infartos pulmonares e hepatopatias (hepatites, cirroses etc.) (15). Tais informa- ções vêm sendo confirmadas através dos diferentes trabalhos publicados desde então, fazendo alguns autores, apenas, leve menção a casos de hepatopatias acompanhados de elevação dos niveis séricos de CPK, atribuindo-os às lesões cardíaca ou muscular esquelética concomitante, ainda que em níveis subclínicos (13). De qualquer modo, parece definitivamente conceituado, em têrmos dos conhecimentos atuais, o fato de que a CPK não se eleva nos soros dos pacientes portadores de hepatites. Isto, entretanto, não impediria que a determinação enzimática pudesse vir a ser utilizada no diagnóstico diferencial das icterícias, estando a sua importância na dependência do conhecimento das patologias que se quisessem diferenciar.

Com as últimas enchentes ocorridas nos Estados da Guanabara e do Rio de Janeiro, passou-se a observar um maior

Trabalho dos Departamentos de Patologia e Medicina Interna (Serviço de Doenças Infecclosas e Parasitárias) da Faculdade de Medictna da Universidade Federal Fluminense.

** Professor Titular do Departamento de Patologia da F.M. da U.F.F.

*** Assistente no Serviço de Doenças Infecciosas e Parasitárias no Departamento de Medicina Interna da F.M. da U.F.F.

**** Chefe do Serviço de Anatomta Patológica do Departamento de Patologla da F.M. da U.F.F. ***** Professor Titular da Disciplina de Clínica de Duenças Infecciosas e Parasitártas da F.M. da U.F.F.
e da U.F.R.J.

Recebido para publicação em 20-9-1971 
número de casos de icterícias por lesāo hepática pelas leptospiras $(5,7,8,9,10$, 11 e 12). Pelas dificuldades de isolamento da bactéria, procurava-se, em têrmos laboratoriais, o diagnóstico por meios indiretos, tais como os comportamentos das transaminases glutâmicas oxalacética e pirúvica (sempre menos elevadas), em relação às bilirrubinas séricas; o do hemograma (compatível com infecção bacteriana) e a das provas funcionais renais (sempre alteradas, nas leptospiroses), comparadas com o que, habitualmente, ocorria nas hepatites virais, a principio, admitidos empìricamente $e$, mais tarde, explicados à luz da microscopia eletrônica (2). Apesar de tôdas as tentativas, não se tem conseguido impor aos laboratórios de rotina meios para o cultivo da leptospira e nem tampouco dispô-los de soros necessários às reações imunológicas diagnósticas. Ao lado de um maior conhecimento das alterações clínicas ocorridas com as infecções, a ponto de permitir o diagnóstico etiológico pela observação, apenas, do tipo do icterícia, o aspecto da impregnação biliar muco-cutânea, associada à congestão e hemorragia que, com freqüência, a acompanha, procurou-se desenvolver os métodos laboratoriais diagnósticos. Com isto, surgiram as biópsias musculares e, com o seu estudo, a idéia de averigüar o comportamento sérico enzimático resultante das lesões observadas.

A CPK ou ATP: creatino fosfotransferase encontra-se principalmente na musculatura esquelética $(2.000 \mathrm{U} / \mathrm{g}$ de proteína) e cardíaca $(670 \mathrm{U} / \mathrm{g}$ de proteína), faltancio, por completo, nos eritrócitos e órgãos parenquimatosos (6). Esta enzima músculo-específica pertence ao grupo das fosfotransferases, com um grupo nitrogenado como aceptor e cataliza a reação específica:

ATP + creatina $\underset{\mathrm{pH}}{\stackrel{\mathrm{pH}-7}{\rightleftarrows}} \mathrm{ADP}+$ fosfocreatina

na qual a fosfocreatina, principal fração fosforada dos músculos dos vertebrados, cede sua ligação fosfórica ao ácido adenosindifosfórico (ADP), em realidade, adenosinpirofosfórico, que passa, a um nível energético mais elevado, a ácido adenosintriforfórico (ATP), que proporciona ao músculo a energia química que se transformará em trabalho.

\section{MATERIAL E MÉTODOS}

Foram realizadas 28 determinações das atividades enzimáticas da CPK nos soros de 22 pacientes internados nos Serviços de Doenças Infectuosas e Parasitárias do Hospital Universitário Antônio Pea̛ro e do Hospital Universitário Luiz Palmier, no período de outubro de 1966 a abril de 1971, cóm o diagnóstico de leptospirose baseado nos dados clínicos e confirmado por reações de sôro-aglutinação.

Os dados referentes a sexo, idade, côr e evolução são apresentac̆os no Quadro I.

Vinte determinações foram feitas na fase aguda da doença e oito fora dela; destas, cinco constituíram-se em reavaliação de pacientes estudados na fase aguda $e$ duas foram determinadas num mesmo doente, alcançado em convalescença.

Em dezesseis dêstes doentes teve-se oportunidade de estudar, histològicamente, as lesões musculares, sendo que dois em material de autópsia e quatorze por biópsia muscular, após a retirada da amostra sangüínea. Nestes casos, ambos os estudos foram feitos na fase aguda da doença, à exceção do de número 14, cuja biópsia só foi realizada com 24 dias de evolução, face aos intensos fenômenos hemorrágicos que apresentava, na época da internação; e do de número 5, no qual a biópsia só foi realizada no $35^{\circ}$ dia da doença.

O material obtido por biópsia do gastrocnêmio era fixado em formalina a $10 \%$, as preparações coradas por hematoxilinaeosina, hematoxilina-fosfotungstica de Mallory e tricrômico de Gomori, $O$ sangue, enviado ao laboratório tão logo fôsse separado o sôro, era submetiơo à dosagem enzimática.

Por dificuldades na obtenção dos substratos e reativos necessários à realização das determinações laboratoriais, foram utilizados dois métodos disponíveis no comércio: (1) método de Okinaka e col. (procedimento 661: Sigma Chemical Company, St. Louis, Missouri, USA), segundo o qual a creatina é convertida em fosfocreatina, com conversão de adenosintrifosfato $\mathrm{em}$ 
adenosindifosfato; a fosfocreatina é hidrolisada a creatina e fosfato inorgânico, e o fosfato é medido, colorimètricamente, pelo método de Fiske e Subarrow $(4,8)$ - os valôres normais sugeridos para esta técnica são compreendidos entre 0 e 12 uni- dades (U.S.); (2) método de Oliver (CPK/ Calsuls: Calbiochem, Los Angeles, Califórnia, USA), usando as modificações sugeridas por Hess e cols. Nesta técnica, a reação da CPK é cuplada a uma reação indicadora:

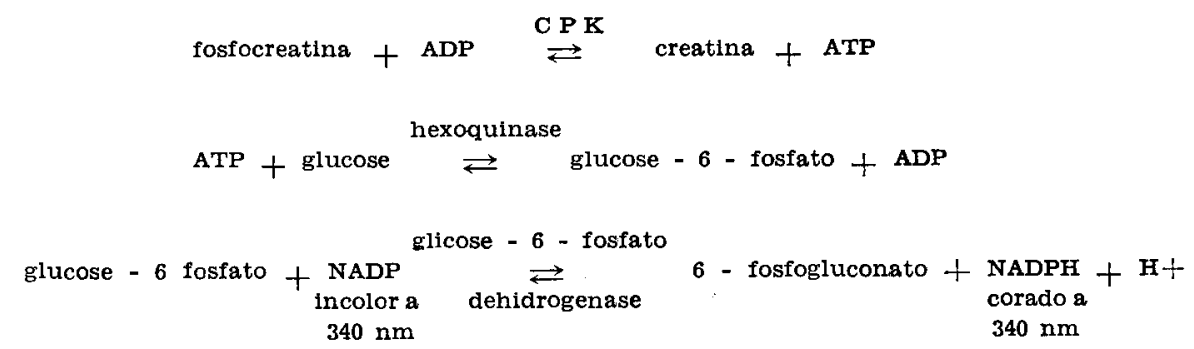

Quadro I

RELAÇÃO DOS CASOS DE LEPTOSPIROSES COM OS TITULOS DE CPK EM DIVERSAS FASES EVOLUTIVAS

\begin{tabular}{|c|c|c|c|c|c|c|c|c|}
\hline $\begin{array}{c}\text { Caso } \\
\text { No }^{\circ}\end{array}$ & Iniciais & Registro & $\begin{array}{l}\text { Idade } \\
\text { (anos) }\end{array}$ & Sexo & Côr & C.P.K. & $\begin{array}{l}\text { Tempo } \\
\text { de } \\
\text { doença }\end{array}$ & $\begin{array}{l}\text { Evo- } \\
\text { lução }\end{array}$ \\
\hline 1 & MRS & 708 & 22 & $\mathbf{M}$ & $\mathrm{Br}$. & 19,0 u.s. & 12 dias & curado \\
\hline 2 & ASG & 976 & 48 & $\mathbf{M}$ & $\mathrm{Br}$. & 13,0 u.S. & 7 dias & curado \\
\hline 3 & $\mathrm{AC}$ & 980 & 57 & $F$ & Pt. & 14,0 u.S. & 2 dias & curada \\
\hline 4 & $\mathrm{AD}$ & 1006 & 49 & $\mathbf{M}$ & Mest. & 27,0 u.s. & 8 dias & óbito \\
\hline 5 & HMP & 1044 & 63 & $\mathrm{M}$ & $\mathrm{Br}$. & 15,0 u.S. & 8 dias & curado \\
\hline 6 & MSL & 1122 & 31 & $\mathbf{M}$ & Pt. & $\begin{array}{r}32,0 \text { u.S. } \\
7,0 \text { u.s. }\end{array}$ & $\begin{array}{l}15 \text { dias } \\
22 \text { dias }\end{array}$ & curado \\
\hline .7 & CPS & 1199 & 27 & $\mathbf{M}$ & Mest. & 36,0 u.s. & 11 dias & curado \\
\hline 8 & GVS & 1200 & 18 & $\mathrm{M}$ & Mest. & $\begin{array}{r}12,5 \text { u.s. } \\
6, \text {. }\end{array}$ & 23 dias & curado \\
\hline $\begin{array}{r}9 \\
10\end{array}$ & $\begin{array}{l}\text { SGO } \\
\text { GMB }\end{array}$ & $\begin{array}{l}1205 \\
1226\end{array}$ & $\begin{array}{r}4 \\
46\end{array}$ & $\begin{array}{l}\mathrm{M} \\
\mathrm{M}\end{array}$ & $\begin{array}{l}\text { Mest. } \\
\text { Mest. }\end{array}$ & $\begin{array}{r}6,6 \text { u.S. } \\
52,0 \text { u.S. }\end{array}$ & $\begin{array}{l}18 \text { dias } \\
11 \text { dias }\end{array}$ & $\begin{array}{l}\text { curado } \\
\text { curado }\end{array}$ \\
\hline & & & & & & 7,1 u.s. & 24 dias & \\
\hline 11 & EFS & 1463 & 25 & M & Mest. & $617,4 \mathrm{mU}$. & 6 dias & curado \\
\hline 12 & MS & 1465 & 25 & M & Pt. & $270,0 \mathrm{mU}$ & 4 dias & curado \\
\hline 13 & IAF & - & 19 & $\mathbf{F}$ & $\mathrm{Br}$. & $\begin{array}{l}40,2 \mathrm{mU} \\
10,6 \mathrm{mU}\end{array}$ & $\begin{array}{l}10 \text { dias } \\
20 \text { dias }\end{array}$ & curada \\
\hline 14 & HAF & 1500 & 19 & $\mathbf{F}$ & $\mathrm{Br}$. & $43,2 \mathrm{mU}$ & 10 dias & curada \\
\hline 15 & AJGA & 1505 & 37 & $\mathbf{M}$ & $\mathrm{Br}$. & $136,0 \mathrm{mU}$. & 4 dias & óbito \\
\hline 16 & AO & 1554 & 30 & $\mathrm{M}$ & Pt. & 220,0 u.S. & 5 dias & curado \\
\hline 17 & JCL & 1672 & 32 & $\mathbf{M}$ & $\mathrm{Br}$. & $\begin{array}{rll}8,0 & \text { u.S. } \\
15,0 & \text { u.s. }\end{array}$ & $\begin{array}{l}13 \text { dias } \\
22 \text { dias }\end{array}$ & curado \\
\hline 18 & GM & 1677 & 35 & $\mathbf{M}$ & $\mathrm{Br}$. & 49,0 u.S. & 9 dias & curado \\
\hline 19 & JCM & 1691 & 35 & M & $\mathrm{Br}$. & 13,5 u.s. & 12 dias & curado \\
\hline $20^{\circ}$ & ASS & LT. 9987 & 26 & $\mathbf{M}$ & Pt. & 11,5 u.s. & 8 dias & curado \\
\hline 21 & EJX & LT. 12314 & 32 & $\mathbf{M}$ & Mest. & 29,0 u.S. & 5 dias & curado \\
\hline 22 & MEL & LT. 12790 & 22 & $\mathbf{M}$ & $\mathrm{Br}$. & 32,0 u.s. & 4 dias & curado \\
\hline
\end{tabular}


A redução do NADP é medida espectrofotométrica a $340 \mathrm{~nm}$. Rozalki sugere como limites de normalidade para esta técnica, de 5 a $30 \mathrm{mU}$ para mulheres e de 5 a 50 para homens, e Hess e cols. o a 40 para ambos os sexos $(3,8)$.

Para têrmos de comparação foram determinadas as ativiciades da CPK nos soros de 20 pacientes adultos, ictéricos, com elevadas atividades séricas das transaminases glutâmicas oxalacética e pirúvica, diagnosticados como portadores de hepatites a virus.

\section{HISTOPATOLOGIA}

O estudo histopatológico realizado em tecido muscular estriacio de 14 casos observados em fase aguda nos mostrou a constância de lesões parenquimatosas que variaram desde simples tumefação turva, com ou sem perda de estriações transversais, até a necrose com ruptura das fibras. E de interêsse chamar a atenção para o achado, em uma mesma biópsia, de diferentes tipos de lesões, certamente fases evolutivas de um mesmo processo agressivo cuja característica básica foi a sua distribuição focal atribuída à presença das bactérias. Não tivemos por objetivo a evidenciação das leptospiras por métodos especiais de coloração, preferindo acompanhar a opinião dos diferentes autores a respeito $(1,5)$.

Com efeito, encontramos em todos os casos lesões de tipos degenerativo e necrótico, incluindo dentre as primeiras a tumefação turva, a basofilia, a perda de estriações, as vacuolizações fina e grosseira, bem como a hialinização tipo Zenker do sarcoplasma, tôdas tidas como reversíveis, que tendem a desaparecer na evolução para a cura, sem deixar reliquats.

Não deixamos de encontrar em nenhum dêstes 13 casos a necrose de aspecto hialino, ora uniforme, ora granuloso, mas sempre restrita a algumas fibras de um mesmo feixe muscular ou a segmentos de uma mesma fibra, mas nunca de todo o feixe, mesmo nos casos fatais. Nas lesões mais graves, sempre em correspondência com a gravidade da evolução clínica, notamos muitas fibras reduzidas ao seu manguito sarcolêmico ou delgada faixa de denso sarcoplasma basófilo exibindo múltiplos núcleos, algumas vêzes tumefeitos, dispostos em cadeia.
Em contraposição, as lesões intersticiais, bastante variáveis, foram discretas na maioria dos casos. A congestão vascular difusa e infiltração homerrágica, mais freqüente nos focos de necrose, atingindo, por vêzes, o interior das fibras, foram encontradas em menos da metade dos casos. $O$ infiltrado inflamatório, representado por elementos mono e polimorfonucleares neutrófilos, distribuiu-se predominantemente ao nivel das áreas de necrose, tornando-se bastante discreto à medida que delas se afastava; sua intensidade náo correspondeu ao grau de necrose e, não raro, deixou de existir. Por vêzes, notaram-se fibras musculares necróticas infiltradas por histiócitos e polimorfonucleares neutrófilos que invadiam as fibras no afã de promover a fagocitose do material morto, a fim de permitir a regeneração, nem sempre completa, provàvelmente partida da reação dos núcleos subsarcolêmicos.

Dois dos três casos biopsiados fora da fase aguda da doença (no 5 e no 14) exibiram focos de fibrose a cujos niveis algumas fibras musculares mostravam hiperplasia dos núcleos subsarcolêmicos com cromatina densa e, raras vêzes, basofilia do sarcoplasma, ambos os aspectos tomados como caráter regressivo das lesões impostas na fase aguda. Em nenhum dêles foram identificadas áreas de necrose. O terceiro ( $n$ o 8) constituiu-se numa exceção, já que, biopsiado aos 23 dias de evolução, mostrava lesões correspondentes ao período agudo, com necrose de fibras, embora mais tarde viesse a evoluir para a cura, não tendo sido repetido o ato cirúrgico.

\section{COMPORTAMENTO ENZIMATICO}

A atividade da CFK determinada nos soros dos 22 pacientes estudados neste trabalho comportou-se, pràticamente, em concordância com os quadros clínico e histopatológico apresentados pelos mesmos no momento da obtenção da amostra sangüinea.

Das 19 determinações realizadas na fase aguda 17 mostraram-se acima dos valôres normais; 5 foram repetidas fora dêste período e apresentaram-se dentro dos limites de normalidade. Dos 2 casos que se constituíram em exceções ( $n^{0} 17$ e no 20), um dêles ( $n \div 20)$ alcançou valor máximo do normal (11,5 u.S.) aos 8 dias de doença, 


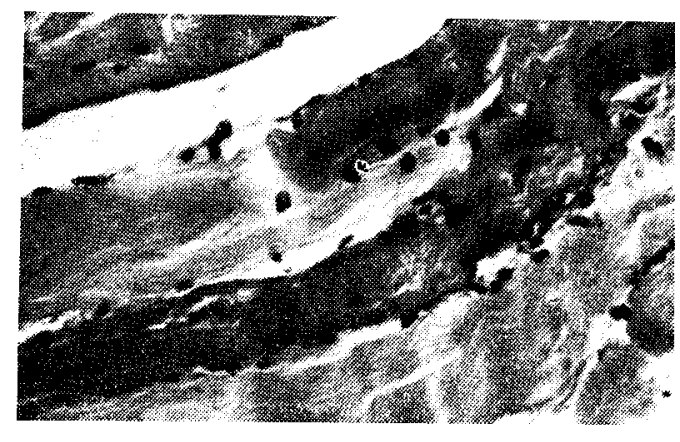

Fig. 1

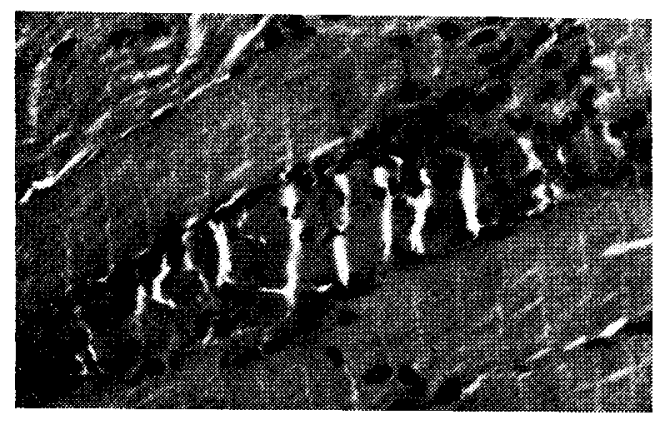

Fig. 2

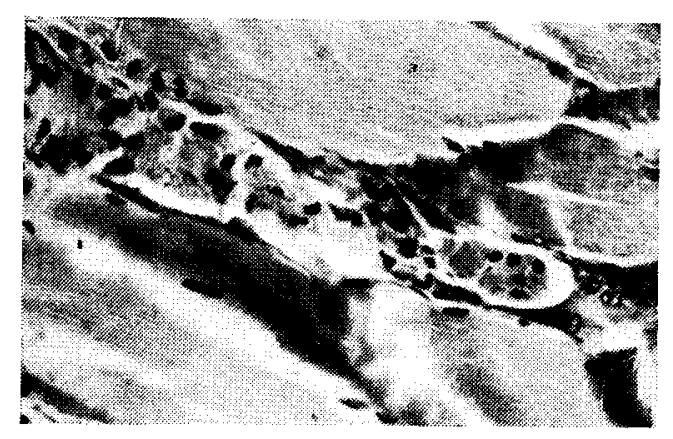

Fig. 3

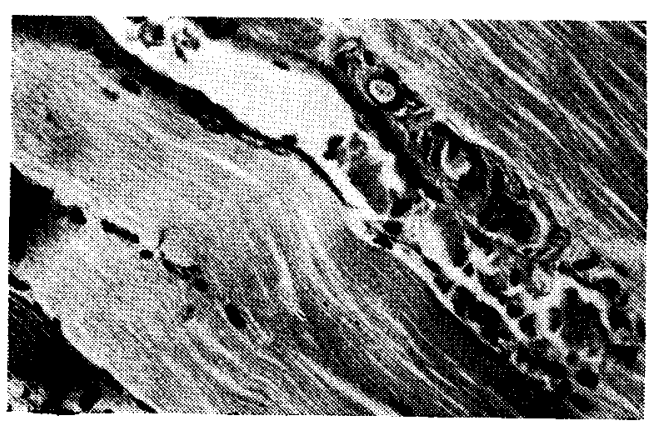

Fig. 4

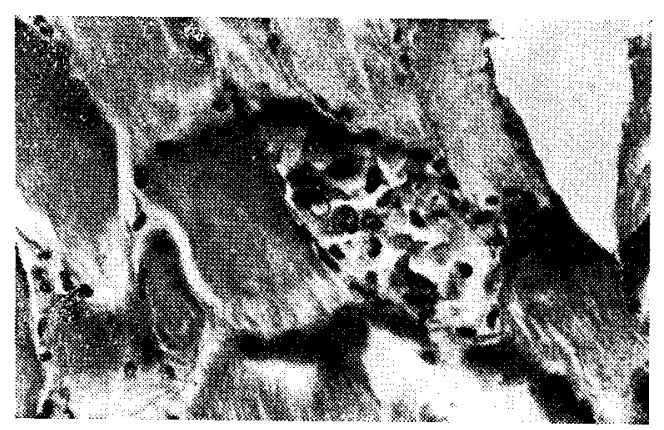

Fig. 5

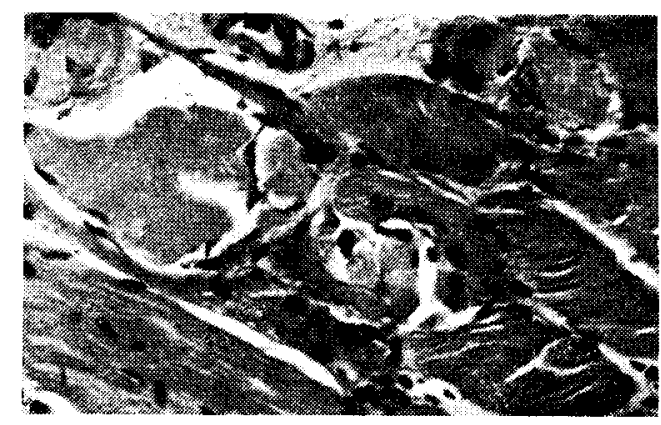

Fig. 6

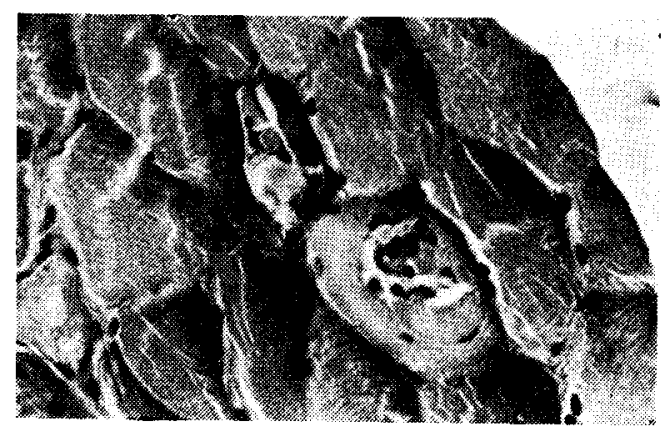

Fig. 7

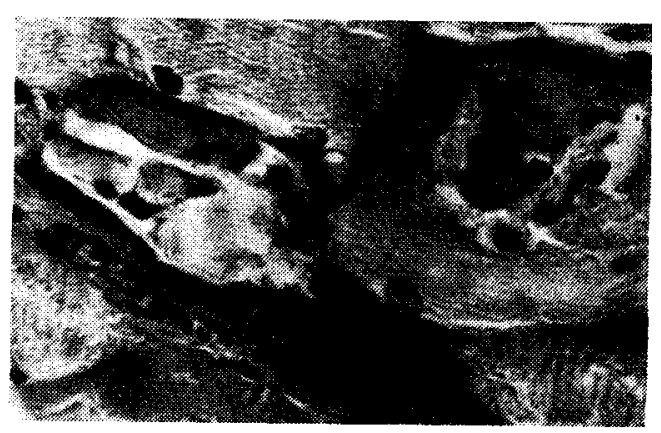

Fig. 8 
Fig. 1 - Fibra muscular exibindo enrugamento das miofibrilas, basofilia sarcoplasmática e hiperplasia de núcleos subsarcolêmicos observada num dos extremos (caso n* 22 H.E. $-\times 250$ ).

Fig. 2 - Fibra muscular exibindo necrose hialina e infiltraçáo sarcoplasmática por histióticos; alguns núcleos subsarcolêmicos caem para o interior da fibra (caso no 20 - H.E. $-\times 250$ ).

Fig. 3 - Fibra muscular necrose hialina, fragmentação sarcoplasmática e infiltrado constituido por fagócitos que alcançam o seu interior; à direita notam-se núcleos subsarcolêmicos tumefeitos, com nucléolos evidentes (caso no $21-$ H.E. $-\times 250$ ).

Fig. 4 - Necrose grave de fibra muscular esvaziada por desintegraçāo do sarcoplasma 'reduzido a pequenas porçóes basófilas subsarcolêmicas e fragmentos de massa hialina distribuícos em meio a histiócitos e polimorfonucleares (caso n' $21-$ H.E. $-\times 250$ ).

Fig. 5- Necrose grave da fibra muscular invadida por polimorfonucleares $\mathrm{e}$ histiócitos em meio a alguns núcleos subsarcolêmicos e massas hialinas residuais do sarcoplasma (caso no $21-$ H.E. $-\times 250$ ).

Fig. 6-Fibras musculares com necrose hialina; observa-se hiperplasia dos núcleos subsar colêmicos dispostos em cadeia na fibra que ocupa o centro do campo microscópico (caso $\mathrm{n}^{\circ} 16-$ H.E. $\times 250$ ).

Fig. 7 - Corte transversal de fibras musculares com necrose parcial ,hialinização e fragmentação do sarcoplasma que numa delas reduz-se à porção subsarcolêmica intensamente basófila encerrando núcleos hiperplásicos dispostos em cadeia (caso n' 21 H.E. $-\times 250$ ).

Fig. 8 - A flbra muscular da direita mostra desintegração parcial do sarcoplasma e acha-se infiltrada por polimorfonucleares e histiócitos; a fibra da esquerda, por necrose hialina, acha-se reduzicia ao sarcoplasma da periferia que se mostra intensamente basófilo e no qual os núcleos subsarcolêmicos, dispostos em cadeia, tornam-se tumefeitos e encerram nucleólos evidentes (caso no $21-$ H.E. $-\times 500$ ). 


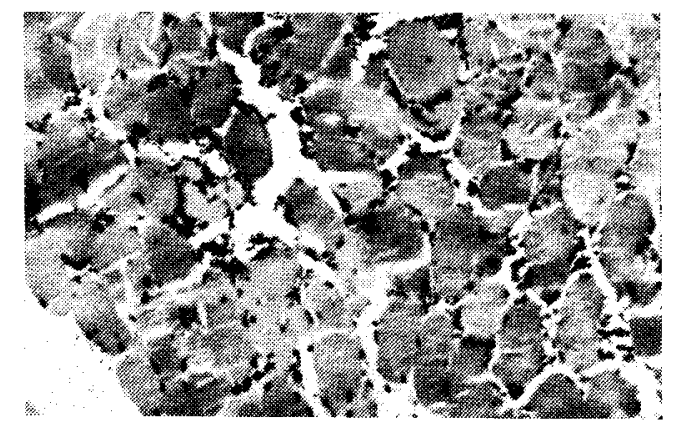

Fig. 9
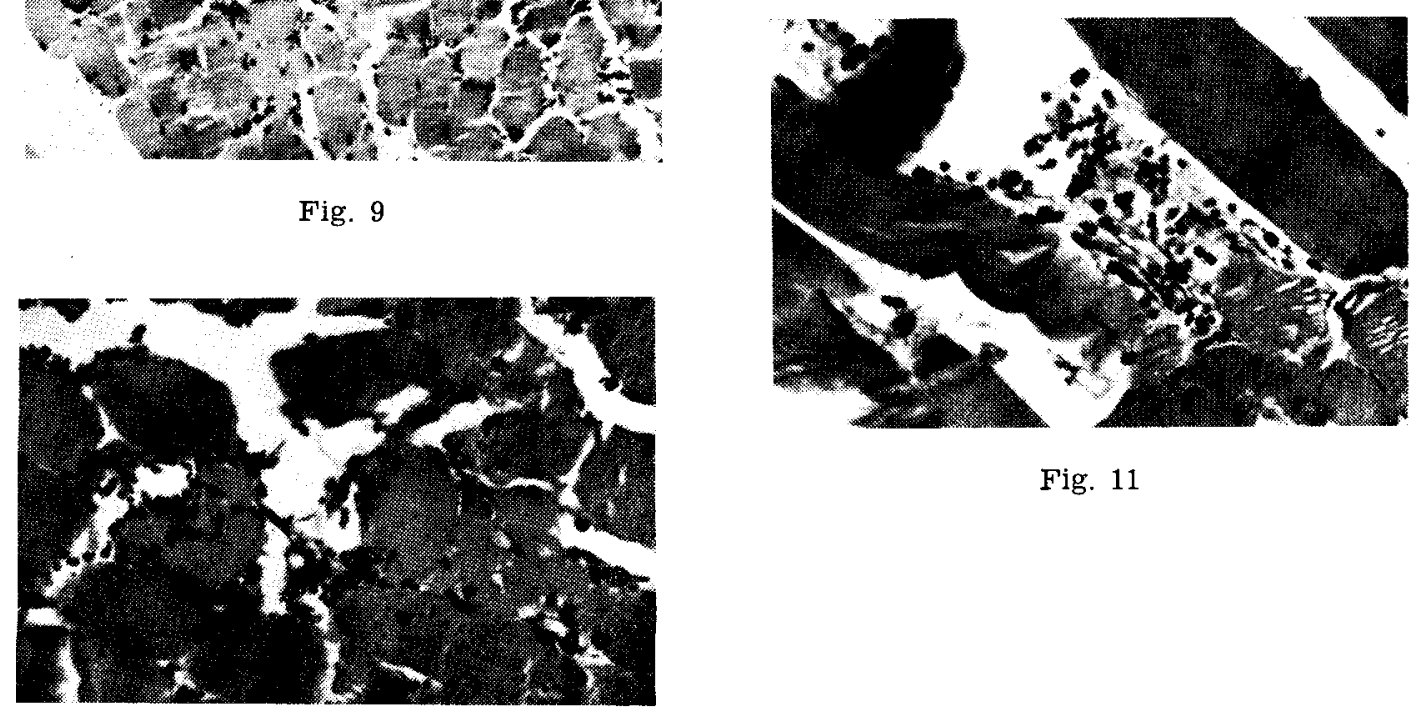

Fig. 11

Fig. 10

Fig. 9-- Hemorragia interstictal difusa alcançando maior intensidade nas proximidades de fibras em necrose (caso no 20 - H.E. $-\times 125$ ).

Fig. 10 - Hemorragia intersticial e fibras musculares com necrose hialina e vacuolização sarcoplasmáticas (caso no $20-$ H.E. $-\times 250$ ).

Fig. 11 - Rutura da fibra muscular acompanhada de hemorragia e infiltrado polimorfonuclear para o interior da baínha sarcolêmica esvaziada pela retraçăo do sarcoplasma (caso n. $16-$ H.E. $-\times 250$ ). 
e o outro ( $\left.\mathrm{n}^{\circ} 17\right)$, tendo repetida a dosagem 9 dias depois, veio a apresentar elevação do nível enzimático acima do normal.

Em dois casos (n. 8 e n. ${ }^{\circ}$ 9) a CPK foi avaliada por 3 vêzes, apenas na fase de convalescença, e não apresentou alteraçōes significativas. $O$ caso no 8 comportouse estranhamente, já que, mesmo estudado aos 23 dias de evolução da doença para a cura, mostrou atividade enzimática elevada, ainda que nas proximidades dos limites normais; a biopsia muscular realizada no mesmo dia evidenciou necrose de algumas fibras, nāo observada em nenhum dos dois outros casos também biopsiados na fase convalescente ( $n^{\circ} 5$ e $n^{\circ}$ 14). Dêstes, em apenas 1 ( $n$ ㅇ 14) foi avaliada a CPK nesta fase e se encontrava em niveis normais.

Os pacientes que, submetidos à biópsia muscular, evidenciaram fenômenos de necrose ao exame histopatológico, apresentaram a CPK elevada no sôro. Constituiram exceçc̃es os casos de n. ${ }^{\circ} 17$ e n. ${ }^{\circ} 20$, em que os estudos histológicos, realizados em material obtido dentro das 24 horas após a retirada da amostra sangüínea, apesar de mostrarem áreas de necrose das fibras musculares, não se fizeram acompanhar de elevações séricas enzimáticas. No caso nọ 20 não se repetiu a determinação da atividade da CPK e no de n. ${ }^{\circ} 17$, 9 dias após a primeira dosagem, a CPK alcançou 15 u.S.

A avaliação da CPK nos pacientes portadores de hepatite a virus mostrou-se dentro dos limites normais, variando de 3,0 a 11,5 u.S., com um valor médio de 8,14 .

No Quadro I são expostos os resultados das dosagens enzimáticas dos pacientes com leptospirose, em relação ao número de dias de evolução da doença em que foram realizadas.

\section{CONCLUSÕES}

A determinação da atividade enzimática da CPK nos soros de pacientes portadores de leptospirose mostrou-se de grande valia no diagnóstico da doença, já que alcançou sempre valôres acima dos considerados como normais, acompanhando a patologia muscular esquelética que a caracteriza em sua fase aguda. Apesar de têrmos encontrado lesões necrotizantes em todos os casos que nesta fase mostraram elevados niveis séricos da enzima em questão, não acreditamos cue apenas a necrose das fibras musculares seja responsável pelo evento, mas que alterações degenerativas graves, ainda reversiveis, possam, a exemplo do que se admite ocorrer com outras enzimas, e em outros tecidos, aiterar os fenômenos de permeabilidade da membrana celular da fibra muscular e permitir o transvazamento de enzimas sarcoplasmáticas para o interstício e luz vascular.

$\mathrm{Na}$ fase convalescente as lesões musculares eram discretas e a CPK não ultrapassou os limites de normalidade admitidos neste trabalho.

Não nos foi possivel determinar o valor prognóstico da atividade enzimática, já que as repetições das dosagens só foram possíveis em 6 casos, dentre os quais não se acham incluidos os 2 óbitos. Por outro lado, não tivemos poor objetivo considerar a influência das lesões renais sôbre os níveis da enzima nos soros dêstes doentes, o que nos daria, certamente, subsídios de muito valor a respeito. De qualquer maneira, parece-nos ter ficado patente a correlação entre os niveis enzimáticos séricos e a gravidade da lesão muscular.

O maior valor da determinação da atividade da CPK nos soros dos pacientes com leptospirose reside, sem dúvida, no diagnóstico diferencial com ictéricos, em que a necrose da célula hepática constitui Q substrato anátomo-patológico, como nas infecções virais, já que nestes, por ausência de lesões musculares graves em sua patologia, a enzima não se altera, tal como ocorreu no grupo de contrôle e como a literatura já referia, constituindo-se em exceções a esclarecer os casos que assim não se comportarem.

Evidentemente, não podemos afastar o diagnóstico de leptospirose de um paciente apenas por apresentar no sôro a CPK em niveis normais, assim como não é válido o diagnóstico apenas tendo por base a elevação da atividade sérica da enzima. O objetivo do trabalho foi mostrar a validade do estudo do comportamento sérico da CPK como mais um dado complementar ao diagnóstico das leptospiroses, assim como a sua significação como prova laboratorial no diagnóstico diferencial das hepatites. 


\section{$S U M M A R Y$}

The authors study the behaviour of the serum activity of CPK among 22 patients with leptospirosis. Its rise was observed during the acute stage of the disease in close relationship with the lesions of the striated muscle as shown by histological sections studied in 13 cases. The clinical and histological pictures were related to the CPK activity. The main purpose of the present work has been to demonstrate the importance of the CPK serum activity as one more point to complement the diagnosis of leptospirosis, as well its importance as a laboratory aid in the differential diagnosis of icterus.

\section{BIBLIOGRAFIA}

1 - ADAMS, RAYMOND D.; DENNYBROWN, D.; and PEARSON, CARL M. - Diseases of muscle, a study in pathology. Ed. 2nd. Hoeber Medical Book. New York, U.S.A., 1967.

2 - BRITO, T. - On the pathogenesis of the hepatic and renal lesions in leptospirosis. Rev. Inst. Med. Trop. São Paulo, 10: 238-241, 1968.

3 - CALBIOCHEM - CPK Stat-pack. Calbiochem, Los Angeles, California, U.S.A., 8 - 1969.

4 - CROWLEY, LEONARD V., and ALTON, SISTER MARY _ A comparison of four methods for measuring creatine phosphokinase. Amer. J. Clin. Path. 53: 948-955, 1970.

5 - GUEDES E SILVA, J.B.; PAIVA, L. M.; PEREIRA DA SILVA, J.J.; BARRETTO NETTO, M.; COURA, J.R. - A biópsia muscular no diagnóstico das leptospiroses. Rev. Soc. Bras. Med. Trop. 3: 306-316, 1969.

6 - LóPEZ, JOSÉ CHABÁS - Enzimologia. Editorial Científico-Médica, Barcelona (España), 357-362, 1969.

7 - PEREIRA DA SILVA, J.J.; PAIVA, L.M.; SOUZA NETTO, B.A.; GUEDES E SILVA, J.B.; COURA, J.R. Estudo preliminar das leptospiroses no Estado do Rio de Janeiro - Rev. Soc. Bras. Med. Trop., 2: 317-337, 1968.
8 - PEREIRA DA SILVA, J.J. - Estudo epidemiológico das leptospiroses no Estado do Rio de Janeiro. Relatório apresentado ao Conselho Nacional de Pesquisas, 1968.

9 - PEREIRA DA SILVA, J.J. e SALINAS, L.F. - Aspectos clínicos da leptospirose - Em publicação.

10 - RIOS GONÇALVES, A.J. e OLIVEIRA ESTELLA, M.R. - Doença de Weil simulando obstrução do colédoco. Bol. Cent. Est. Hosp Serv. Est. (GB). 19: 127-133, 1967.

11 - RIOS GONÇALVES, A.J.; SANTINO FILHO, F; DUARTE, F. - Doenças de Weil. Bol. Cent. Est. Hosp. Serv. Est. (GB) . 19: 147-166, 1967.

12 - RIOS GONCALVES, A.J.; QUAGLIATO JUNIOR, R.; FERREIRA, M.; ABREU, T.J.; HOETTE, M. - Leptospiroses no H.S.E. Janeiro a outubro de 1969 .

13 - SAVIGNANO, T.; HANOK, A.; and KUO, J. - Creatine phosphokinase activity. Amer. J. Clin. Path. 51: 76-85, 1969 .

14 - SHELDON, W.H. - Lesions of muscle in spirochetal jaundice (Weil's disease; spirochetosis iterohemorrhagica). Arch. Int. Med. 75: 119, 1945.

15 - SIGMA TENTATIVE TECHNICAL BULLETIN No 661 - Creatine phosphokinase (CPK) in serum or other fluids. Sigma Chemical Company, St. Louis, Missouri, U.S.A., may. 1967. 